\title{
TAKI ONQOY: EPIDEMIA DE INTOXICACIÓN POR EXPOSICIÓN AL MERCURIO EN HUAMANGA DEL SIGLO XVI
}

\author{
Luis Alberto Santa María ${ }^{1,2, a}$
}

\begin{abstract}
RESUMEN
Taki Onqoy es un síndrome que corresponde a la intoxicación por exposición al mercurio. Apareció como consecuencia de la explotación de las minas de mercurio de Paras y Huancavelica en el Perú durante el siglo XVI. La caquexia mercurial, última etapa de la enfermedad, estaría asociada a la idea del pishtaco. El Taki Onqoy en el Perú del siglo XVI, representa la mayor epidemia por intoxicación por mercurio conocida por la humanidad.
\end{abstract}

Palabras clave: Intoxicación por mercurio, Minería, Perú (fuente: DeCS BIREME).

\section{TAKI ONQOY: MERCURY POISONING EPIDEMIC IN 16TH CENTURY HUAMANGA}

\begin{abstract}
Taki Onqoy is a syndrome that corresponds to the poisoning from exposure to mercury. It appeared as a result of the exploitation of the mercury mines of Paras and Huancavelica in Peru during the 16th century. The Cachexia mercurial, the last stage of the disease, would be associated with the idea of pishtaco. The Taki Onqoy in 16th-century Peru represents the largest epidemic of mercury poisoning known to humanity.
\end{abstract}

Key words: Mercury poisoning, Mining, Peru (source: MeSH NLM).

\section{INTRODUCCIÓN}

En Huamanga del siglo XVI, diferentes cronistas reportaron la aparición de una "enfermedad del baile" llamada Taqui Onco. Valdizán ${ }^{(1)}$ consideró que fue una intoxicación atribuible al alcohol o a la coca. Curatola (2) planteó la pelagra como posible causa, y Duviols ${ }^{(3)}$ propuso histeria colectiva asociada a una epidemia de gripe que asoló el virreinato en 1538.

En este artículo demostramos que el Taki Oqnoy describe una epidemia de intoxicación por exposición al mercurio, derivada de la explotación industrial de dicho mineral en las minas de Paras y Huancavelica; el único testimonio gráfico existente de este proceso, es el captado por Guamán Poma durante su visita a Huancavelica, en compañía de Cristóbal deAlbornozen 1571. Las imágenes publicadas en este artículo han sido descargadas del facsímil digital de GKS 2232 4. ${ }^{\circ}$ Guamán Poma de Ayala, Nueva Coronica y buen gobierno $(1615)^{(4)}$, y se publican gracias a la gentil autorización de la Royal Danish Library.

\section{TAKI ONQOY Y MINERÍA}

En 1564, Luis de Olvera reportó que en Parinacochas:

/...quel Marqués Pizarro, quando entró de Caxamalca e venció a los yndios e subjetó este reyno, avía sido porque Dios entonces avía vencido las guacas, pero que agora todas avían resucitado para dalle batalla y vencelle e que las dichas guacas ya no se encorporavan en piedras ni en arboles ni en fuentes, como en tiempo del ynga, sino que se metían en los cuerpos de los yndios y los hazian hablar e de alli tomaron a temblar diciendo que tenían las guacas en el cuerpo y a muchos dellos los tomavan y pintaban los rostros con color colorada y los ponían en unos cercados y allí yvan los yndios a los adorar por tal guaca e ydolo que dezía que se le avía metido en el cuerpo y les sacrificaban carneros, ropa, plata, maíz e otras muchas cosas, de los quales se entendió perescieron muchas animas con la dicha apostasía ${ }^{(5)}$.

Instituto Nacional de Salud. Lima, Perú.

Universidad Nacional Mayor de San Marcos. Lima, Perú.

Médico cirujano, doctor en Salud Publica.

Recibido: 13/03/2017 Aprobado: 07/06/2017 En línea: 28/06/2017 
Olvera describió que el cinabrio ya no seguía el ciclo biológico del mercurio en la biosfera, sino que por la vía respiratoria /...se metían en los cuerpos de los indios y los hazían hablar e de alli tomaron a temblar diciendo que tenían las guacas en el cuerpo.../, refiriéndose a la ataxia ("enfermedad del baile"), disartria ("enfermedad del canto") y muerte por exposición a los vapores mercuriales resultantes de la metalurgia del mercurio impulsada por los españoles desde 1560 en Paras y 1564 en Huancavelica. No es posible considerar que se explotaron millones de toneladas de mercurio, sin protección ocupacional, sin que hubiese casos de intoxicación por exposición a este mineral.

En 1570, Bartolomé Berrocal, asoció el Taki Onqoy a la mita minera:

/...decían los dichos apóstatas que estaban peleando con el dios de los cristianos y que presto sería de vencida y que acabaría su mita de mandar.../(5).

\section{En 1577, Cristóbal de Molina señaló:}

/ e que no hera Dios el que les dava las comidas, si no uno que andava en una manera de canasta en el ayre cave ellos.../(5).

Refiriéndose a la canasta o "sombrero" que se utilizaba en las fundiciones de mercurio, según lo descrito por José de Acosta:

/ La misma filosofía pasa en la plata y oro, que se saca por azogue, porque si es el fuego poco y flojo, no se saca cuasi nada del azogue; si es fuerte, evapora mucho el azogue, y topando arriba con que llaman sombrero, luego se torna en licor y gotea abajo ${ }^{(6)}$.

En 1584, Cristóbal de Molina declaró:

/...porque dezia el don Joan Chocna (sic) que él traya consigo uno que ellos no veyan, el qual le dezía estas cosas y que este les dava las comidas y mantenimientos, ... y les dixeron públicamente que ellos por ser pobres tomaron aquel modo de vivir para poder comer y ganar con ello para su sustento ${ }^{(5)}$.

Revelando que, por la obligación de los tributos, y malas cosechas, los Taki Onqoys se vieron obligados a trabajar en minas (aquel modo de vivir!).

\section{TAKI ONQOY E HISTORIA NATURAL DE INTOXICACIÓN POR EXPOSICIÓN AL MERCURIO}

La exposición minera y metalúrgica al mercurio, sin protección, es un riesgo inherente para la aparición de casos de intoxicación por exposición al mercurio. Por tal motivo, ordenando los reportes de Cristóbal de Albornoz y Guamán Poma, siguiendo la lógica del concepto de historia natural de la enfermedad, se obtiene la Tabla 1 , que describe la historia natural de la intoxicación por exposición al mercurio:

\section{PERIODO PREPATOGÉNICO}

Se identificó la interacción de tres factores clave para la emergencia de la epidemia de intoxicación por mercurio:

Tabla 1. Historia natural de la enfermedad del Taki Onqoy o intoxicación por exposición al mercurio en Huamanga del siglo XVI

\begin{tabular}{|c|c|c|c|c|c|}
\hline \multirow{2}{*}{$\begin{array}{l}\text { Periodo } \\
\text { prepatogénico }\end{array}$} & \multicolumn{5}{|c|}{ Periodo patogénico } \\
\hline & Preclínico & Clínico & gnos propios de la & toxicación por $\mathrm{m}$ & ercurio) \\
\hline $\begin{array}{l}\text { Exposición al mercurio } \\
\text { en minas de Paras y } \\
\text { Huancavelica ( } 5 \text { fases): } \\
\text { 1) Fase minera } \\
\text { (extracción) } \\
\text { 2) Fase metalúrgica } \\
\text { (fundición). } \\
\text { 3) Fase de transporte. } \\
\text { 4) Fase de contaminación } \\
\text { 5) Fase de aplicación del } \\
\text { azogue }\end{array}$ & $\begin{array}{c}\text { Asintomático por } \\
4 \text { horas }\end{array}$ & $\begin{array}{l}\text { 1) Ptialismo } \\
\text { 2) Perdida de } \\
\text { dientes, gingivitis. }\end{array}$ & $\begin{array}{l}\text { 3) Disartria } \\
\text { (enfermedad del } \\
\text { canto). } \\
\text { 4) Cansancio } \\
\text { muscular. } \\
\text { 5) Ataxia o temblor } \\
\text { (enfermedad del } \\
\text { baile). } \\
\text { 6) Deterioro } \\
\text { psíquico: "locos", } \\
\text { "atontados", "juicio } \\
\text { perdido". } \\
\text { 7) Depresión, } \\
\text { timidez excesiva, } \\
\text { irritabilidad, } \\
\text { disminución de la } \\
\text { confianza en sí } \\
\text { mismo. }\end{array}$ & $\begin{array}{l}\text { 8) Alteración } \\
\text { del sueño. } \\
\text { Insomnio. "El } \\
\text { hechicero de los } \\
\text { sueños". } \\
\text { 9) Postración en } \\
\text { cama } \\
\text { 10) Caquexia } \\
\text { mercurial. } \\
\text { Damián de } \\
\text { Jeria: /... } \\
\text { bocanadas de } \\
\text { sangre envuelta } \\
\text { con azogue. } \\
\text { Azogue en } \\
\text { sangrías. }\end{array}$ & $\begin{array}{l}\text { 11) Muerte, } \\
\text { incluye suicidios } \\
\text { Murua: /...y } \\
\text { hallar entre } \\
\text { los huesos } \\
\text { corriendo el } \\
\text { azogue. }\end{array}$ \\
\hline
\end{tabular}

Agentes: mercurio elemental y dimetilmercurio producto de la fundición del mercurio.

Tiempo de Supervivencia estimado por los cronistas: 1 año. 
1). El mercurio, agente causal de la epidemia, cuya explotación en las minas de Paras y Huancavelica, y posterior uso en las minas de Tunsulla, Potosí, entre otras, originó la exposición al mercurio (elemental, orgánico e inorgánico).

2). Los trabajadores de las minas de mercurio de Paras y Huancavelica, (huésped): que progresivamente fueron: Henrique Garcés y sus socios durante la fase de búsqueda y experimentación del mercurio, los esclavos negros contratados por Garcés para explotar las minas de Paras, y la población indígena que se involucró en el trabajo de la mina de mercurio de Huancavelica como mitayo, mingado y asalariado.

3) El ambiente laboral en las minas de mercurio de Paras (Guamanga) y Huancavelica, donde el contexto de poder y codicia por los metales en época de conquista, fue el factor determinante en la aparición de la epidemia conocida como Taki Onqoy.

La explotación minera del mercurio generó cinco fases de exposición al mineral:

1). La fase minera para extracción del mineral.

2). La fase metalúrgica para fundición del mineral (Figura 1).

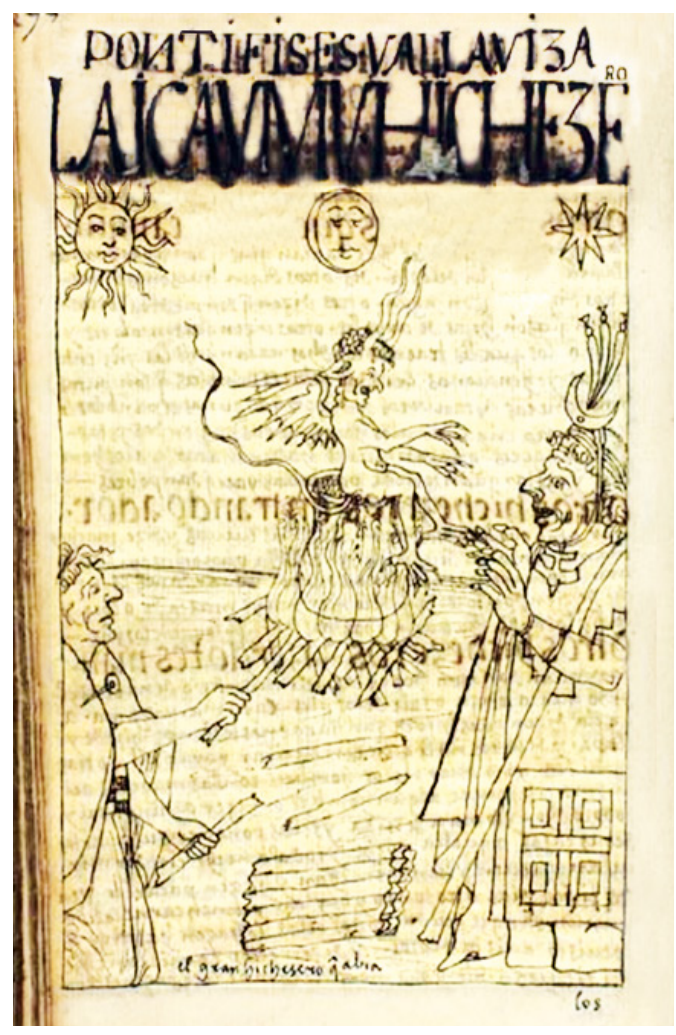

Fuente: http://www.kb.dk/permalink/2006/poma/279/es/text/

Figura 1. Metalurgia del mercurio. Huancavelica, Siglo XVI
3). La fase de transporte del mineral a Bolivia u otras minas, con riesgo de exposición al mercurio:

Que dan por razón, que este metal (azogue) por lo que tiene de venenoso, y por ser tan penetrante, que no hay vasija que no traspase, excepto las vidriadas, o las pieles de valdreses, en que le atan y guardan por algún tiempo, es como tirano de la vida de los hombres, y de los demás metales.../ ${ }^{(7)}$.

4). La fase de contaminación ambiental en lugares aledaños a las minas y hornos de fundición en Huancavelica (Figura 2).

5). La fase de aplicación del azogue en la técnica de amalgamación del oro y la plata en Tunsulla, Potosí y otras minas.

Las cinco fases están asociadas a exposición de tipo ocupacional al mercurio, pues involucran a los trabajadores que ejecutan dichas tareas. La tercera y cuarta fase involucran a población general, arrieros y trabajadores mineros y/o metalúrgicos.

\section{PERIODO PATOGÉNICO}

Durante la etapa preclínica, permanecían asintomáticos a pesar de tener niveles elevados de mercurio en

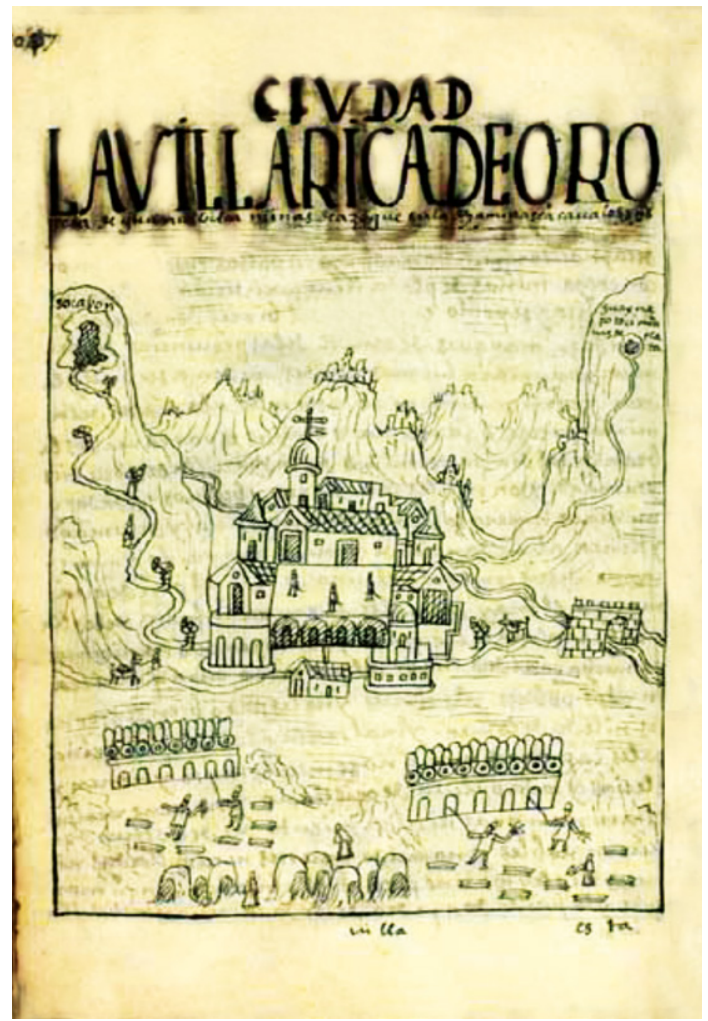

Fuente: http://www.kb.dk/permalink/2006/poma/1055/es/text/?open=idp607984

Figura 2. Hornos de fundición del mercurio en Huancavelica, Siglo XVI 
sangre $\mathrm{u}$ orina, a tan solo cuatro horas de exposición a los vapores de mercurio.

En la etapa clínica se describieron los signos propios de la intoxicación por mercurio:

1) Ptialismo mercurial o pérdida excesiva de saliva, donde el aliento exhala una fetidez insoportable (Figura 3). Signo de exposición aguda al mercurio, que al haber sido graficado por Guamán Poma deAyala indica que fue testigo presencial de estos casos.

2) Gingivitis y pérdida de dientes, como ocurrió con Henrique Garcés y otros afectados por Taki Onqoy.

3) Disartria o "enfermedad del canto". Descrita por Cristóbal de Molina:

Abra diez años (10) años, poco más o menos, que huvo una yrronia entre estos yndios d'esta tierra y era que haçían una manera de canto al qual llamavan taqui hongoy. Porque en la provincia del Parinacocha un Luis de Olivera, clérigo presbítero que a la saçon hera cura del dicho repartimiento, qu'es en el ovispado del Cuzco, fue el primero que vio de la dicha yrronia o ydolatría, él pone aquí de la manera que lo hacian y por qué ${ }^{(8)}$.

Resalta que el signo más frecuente y llamativo en ese momento de la epidemia era la disartria, que es el primer signo que se presenta en epidemias de intoxicación por exposición al mercurio, luego de las parestesias.

4). Cansancio muscular o parestesias, que fue la razón biológica por la cual los españoles suponían que los indios eran "flojos", pero estaban afectados por el mercurio.

5). Ataxia o temblor o "enfermedad del baile". Cristóbal de Molina la describió en los siguientes términos:

$Y$ así fue que obo muchos yndios que temblavan y se rebolcavan por el suelo, y otros tiravan de pedradas como endimoniados haçiendo visajes. Y luego [f.34r[ repossavan, y llegavan a él con temor y le decian que qué avía y sentía, y respondía que la guaca fulana se le avía entrado en el cuerpo. Y luego lo tomavan en braços y lo llevaban a un lugar diputado y allí le haçían un aposento con paja y mantas. Y luego le enbixavan y los yndios le entravan adorar con carneros, colle, chicha, Ilipta, mollo y otras cosas. Y haçían fiestas todo el pueblo de dos y tres días baylando y beviendo, e ynbocando a la guaca que aquel representava y decía tenía el cuerpo, y velando de noche sin dormir ${ }^{(8)}$.

Luego, agregaba:

Durante este tiempo obo diversas maneras de apostaçías en diversas provincias: unos baylavan dando entender tenían de la guaca en el cuerpo, otros temblaban por el mesmo respeto dando a entender la tenían también, otros se ençerravan en sus cassas a piedra seca $y$ davan alaridos, otros se despedaçavan, y despeñavan y matavan, y otros se hechavan en los ríos ofreçiéndose a las guacas, hasta que Nuestro Señor, por su misericordia, fue servido alumbrar a estos miserables ${ }^{(8)}$.

Describió muchos signos de intoxicación por mercurio como la ataxia o "baile" (temblaban y se revolcaban por el suelo, bailaban dando a entender que tenían la guaca en el cuerpo, temblaban); alteraciones de la personalidad (tiraban piedras como endemoniados haciendo visajes, que son movimientos anormales en el rostro por enfermedad, se encerraban en sus casa y daban alaridos); insomnio (de noche sin dormir), y otros se despedazaban y despeñaban y mataban, porque, al caminar, no podían controlar sus movimientos o se suicidaban como consecuencia de la depresión que les generó la intoxicación por mercurio.

6). Deterioro psíquico progresivo, por lo que se les calificaba como "locos", "atontados", y con el "juicio perdido". El mercurio metálico o inorgánico puede ser llevado al hogar en la ropa o zapatos contaminados de un trabajador y, de esta manera, producir intoxicación en niños o familiares que no participaron del proceso de fundición:

I...y que este testigo vido seis o siete muchachos e muchachas yndios que entendian en la dicha seta e apostasía e andaban como tontos y gente como perdido el juicio, todo lo cual el dicho Cristóbal de Albornoz descubrió con su buena maña e yndustria y lo sacó de raíz ${ }^{(5)}$

7). Depresión, timidez excesiva, irritabilidad, disminución de la confianza en sí mismo.

8). Alteración del sueño e insomnio: "El hechicero de los sueños".

\section{9). Postración en cama.}

10). Caquexia mercurial: una de las últimas fases de la intoxicación por mercurio. Estado de extrema delgadez en la que prácticamente se elimina la grasa del cuerpo humano por acción del mercurio:

A estos hichezeros dizen los quales tomauan una olla nueva que llaman ari manca, Que lo cuesen cin cosa nenguna y toma sebo de persona... Y se seca un año $y$ se pone como un palo y se muere ${ }^{(4)}$ (Figura 4$)$.

Estos casos están asociados a la idea de pishtaco en los andes. 


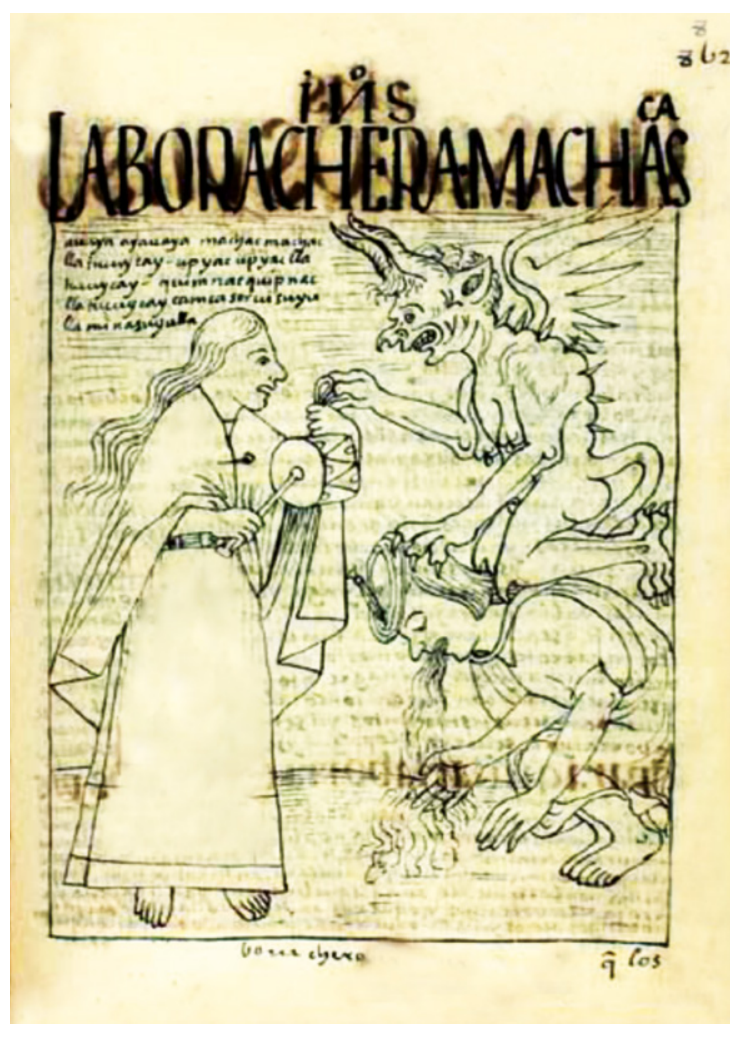

Fuente: http://www.kb.dk/permalink/2006/poma/876/es/text/

Figura 3. Ptialismo mercurial

l...el año de sesenta, y no atrás, de aver tenido y creýdo por los indios que d'España avian enviado a este reyno por unto de los indios [f.33r[ para sanar cierta enfermedad, que no se hallava para ella medicina sino el dicho unto, a cuya causa en aquellos tiempos andavan los yndios muy recatados y se estrañanavan de los españoles en tanto grado que la leña, yerba o otras cosas no lo querían llevar a casa de español, por dezir no los matase allá dentro para les sacar el unto ${ }^{(8)}$.

11). Muerte, incluido el suicidio posdepresión.

El Hospital de Huancavelica reportó como criterios confirmatorios del diagnóstico de intoxicación por mercurio:

a). Durante la ejecución de sangrías, brotaba el azogue.

b). Bocanadas de sangre envuelta con azogue. /...algunos hechando bocanadas de sangre embuelta con azogue el cual también se halla algunas veces cuando los sangran y también en las sepulturas donde los entierran.../(9).

Post mórtem, también se reportó:

a). En sepulturas de hombres muertos se halla azogue, que después de haberlos gastado, él se sale muy a su

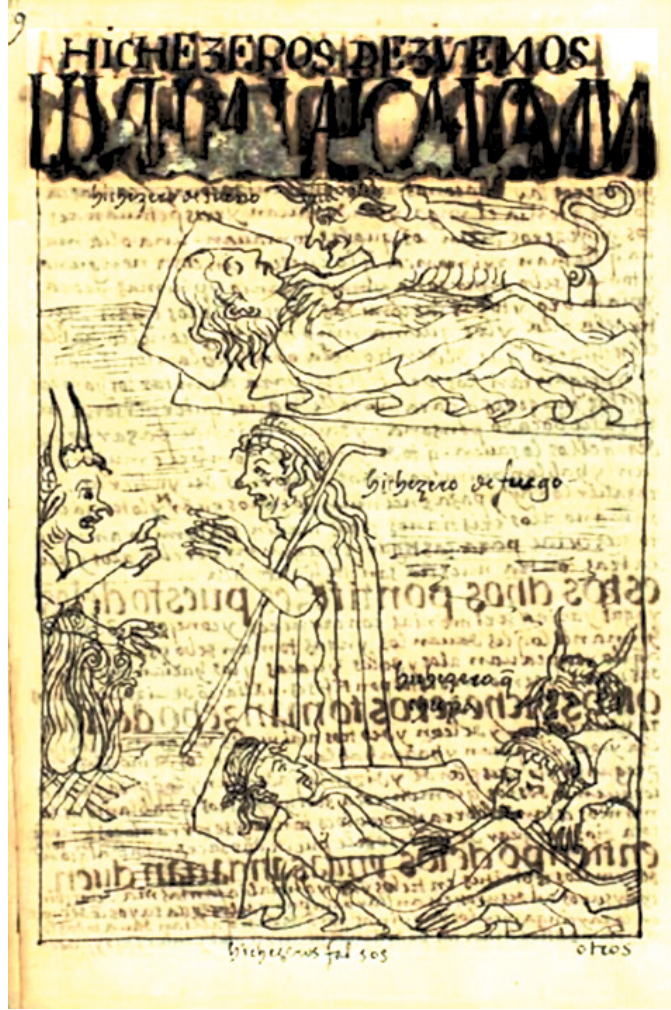

Fuente: http://www.kb.dk/permalink/2006/poma/281/es/text/?open=idp316144

Figura 4. Caquexia mercurial

salvo entero. Háse hallado también en las médulas y tuétanos de hombres o animales, que recibiendo su humo por la boca o narices, allá dentro se congela, y penetra los mismos huesos. Por eso es tan peligrosa la conversación con criatura tan atrevida y mortal ${ }^{(6)}$.

b). Acontece abrir una sepultura donde hay indio enterrado que así murió, para enterrar otro, y hallar entre los huesos corriendo el azogue ${ }^{(10)}$.

En 1570, Gerónimo Martin, dijo:

I...y andarían las cabezas por el suelo y los pies arriba, $y$ otros tornarían guanacos, venados $y$ vicuñas $y$ otros animales, y se despeñarian desatinados, y que las dichas guacas harian otro nuevo mundo y otras gentes, y que esto verían ellos como subcedia asi volviendo ellos a las dichas guacas ${ }^{(5)}$.

Asimismo, describió formas graves de intoxicación por mercurio en seres humanos, y en animales:

I... e que si esto no creyan, los harian torrnar a los yndios en guanacos e vicuñas e otros animales ${ }^{(5)}$. 
El mercurio no es utilizado en ninguna función biológica o fisiológica del cuerpo humano, por lo que su uso siempre ha tenido una motivación cultural.

El termino Taki Onqoy expresa un síndrome, es decir, un conjunto de signos y síntomas que se producen de forma simultánea o consecutiva, que configuran una patología conocida actualmente como intoxicación por exposición al mercurio, que tiene como signos característicos la disartria ("enfermedad del canto") y la ataxia ("enfermedad del baile"). El gran número de casos y mortandad reportados por los cronistas no pueden ser explicados por enfermedades genéticas que también presentan ataxia o corea, ni otras patologías que presentan alteraciones del movimiento corporal.

Esta misma enfermedad luego fue conocida entre los españoles como "enfermedad de la mina", "enfermedad de Huancavelica" o "enfermedad de los azogados", pues presentan el mismo proceso fisiopatológico, la misma expresión clínica e historia natural de la enfermedad.
En todos los casos se verifica que la respiratoria fue la principal vía de acceso de los vapores mercuriales al organismo, confirmándose que cualquiera que fuese la expresión cultural que adopte la enfermedad, el proceso fisiopatológico es el mismo. Este intercambio del aliento humano con los vapores mercuriales por la vía respiratoria, fue interpretado culturalmente como el mecanismo de adquisición del "poder de los cerros".

La identificación del Taki Onqoy como un síndrome o enfermedad obliga a reconsiderar la idea de una medicina exclusivamente mágico-religiosa entre los incas, pues la idea de síndrome no solo se refiere a "síndromes culturales", sino también expresa una forma de producción de conocimiento basado en la observación sistematizada de hechos, lo que forma parte del método científico ${ }^{(11)}$.

Fuentes de financiamiento: autofinanciado.

Conflictos de interés: el autor declara no tener ningún conflicto de interés.

\section{REFERENCIAS BIBLIOGRÁFICAS}

1. Valdizan H. La alienación mental entre los primitivos peruanos. [Tesis doctoral]. [Lima]: Universidad Nacional Mayor de San Marcos; 1915.

2. Millones L. Mesianismo en América Hispana: El Taki Onqoy. Mem am. 2007;15:7-39.

3. Klor de Alva J. DUVIOLS, Pierre. La. destrucción de las religiones andinas (durante la Conquista y la Colonia). Traducción de Albor Maruenda. México, Universidad Nacional Autónoma de México,1977, 479 p., bibliografía, glosario, e índices [Instituto de Investigaciones Históricas, Serie de Historia General, 9]. Historica. 1984;8(2):247-56.

4. El sitio de Guaman Poma. [internet]. The Royal Danish Library. [Citado 26 de octubre de 2016]. Disponible en: http://www.kb.dk/permalink/2006/ poma/info/es/frontpage.htm
5. Millones L, Castro Klarén S. El Retorno de las Huacas: Estudios y documentos sobre el Taki Onqoy. Lima: Instituto de Estudios Peruanos; 1990. p. 67, 91-9, 130, 176-81.

6. Acosta, J. Historia Natural y Moral de Indias. Sevilla: Biblioteca de autores españoles; 1590. Cap VII, X.

7. De Solorzano Pereira J. Política Indiana. Gante: Universidad de Gante; 1703. p. 134. [Citado el 21 de febrero de 2017]. Disponible en: https://goo. $\mathrm{gl} / \mathrm{bzStns}$

8. De Molina C. Relación de las Fabulas y ritos de los Incas. Edición crítica de Paloma Jiménez del Campo: Transcripción paleográfica de Paloma Cuenca Muñoz, coordinación de Esperanza López Parada. Madrid: Iberoamericana, Frankfurt am Main. Vervuert; 2010.
9. Sala Catala J. Vida y muerte en la mina de Huancavelica durante la primera mitad del siglo XVIII. Asclepio. 1987;XXXIX:193-204.

10. Robins NA. Mercurio, Minería e Imperio: El costo humano y ecológico de la minería de plata colonial en los andes. Huancavelica: Universidad de Huancavelica; 2011. p. 198.

11. Santa Maria Juarez LA. Taki Onqoy: Epidemia de Intoxicación por exposición al mercurio en el Perú del Siglo XVI [Tesis doctoral]. [Lima]: Universidad Nacional Federico Villarreal; 2016.

Correspondencia: Luis A. Santa Maria Juárez Dirección: Jr. Capac Yupanqui 1400 -Lima 11, Perú.

Correo electrónico:luchins@hotmail.com 